\title{
RESEARCHING THE LEVEL OF INFORMING OF ELDERLY PEOPLE ABOUT THE HEALTH PREVENTION AND PROPHYLACTICS
}

\author{
Tanya Paskaleva \\ Trakia University of Stara Zagora, Branch of Haskovo \\ 48, "Saedinenie" blvd., Haskovo, Bulgaria \\ phone: +359885333402, e-mail: paskaleva666@abv.bg
}

\begin{abstract}
The awareness plays a conclusive role in raising health realizing. The activities of preventive health require to know the level of health literacy of individuals and how they are informed on issues related to preventive action, and the level of knowledge about the risk factors for diseases available including those for prematurely aging. The aim of the study is to investigate the level of awareness of the elderly for health prevention and prophylaxis. Used is a direct individual anonymous survey among 142 persons aged / older than 65 years for the period January-April 2016. The survey results give us reason to maintain that health prevention is poorly used medical activity, which is basic and the most important for good health, prevention of diseases and prematurely aging. The relative part of the tested, hat have knowledge about healthy lifestyles is low. A major source of information is the media but declare expressed preferences, readiness and desire to be informed from medical professionals - a doctor and nurse. Their contribution to the health education field in present moment is on unsatisfactory level, too modest, with untapped potential.
\end{abstract}

Keywords: awareness, elderly people, health prevention.

\section{INTRODUCTION}

Informing has a decisive role in the increase of the health culture. The activities connected to health prophylactics require that we know the level of health culture of people and to what extent they are informed about questions connected to prophylactic activities, as well as the level of knowledge about the risk factors for the available sicknesses, including the ones, linked to premature ageism.

The unregulated stream of commercial health information in the society leads to confusion and inopportune health activities [1]. Speaking of this, the confidential relations with the medical specialists are significant about the whole specter of medical activities and in many cases influence positive attitude towards health. The efficiency of the communication to a great extent depends on the idea whether these relations are built according to the principles of cooperation, mutual respect and trust. The medical personnel must know very well the mechanisms, needed to form interpersonal relations. Communication with elderly people has its own peculiarities that require the medical information be accessible, sufficient, useful and understandable. The correct and well-made conversation is useful and increases the personal information field with valuable health information. Besides, it can also reduce the psycho-emotional tension, which in many cases accompanies a person when $\mathrm{s} / \mathrm{he}$ visits a medical institution.

\section{AIM}

The aim of the research is to study the level of informing of the elderly people about the health prevention and prophylactics. 


\section{AR'IIL

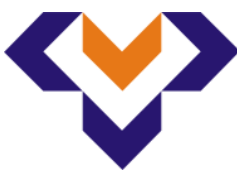

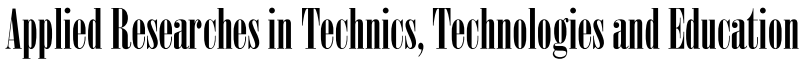

Journal of the Faculty of Technics and Technologies, Trakia University https://sites.google.com/a/trakia-uni.bg/artte/

\section{MATERIALS AND METHODS}

There has been conducted an anonymous questionnaire amongst people aged 65 or more. Methods applied: direct anonymous questionnaire and analysis of the resources. The research has been conducted in the period between January - April 2016.

\section{RESULTS AND DISCUSSION}

In the research took part 142 people. The biggest age group is from 65 to 69 years of age $46 \%$, followed by the one of $70-74-34 \%$ and 75 or older $-20 \%$. The percentage division according to gender is the following: almost two-thirds of the questioned people $(60 \%)$ are women and (40\%) are men. Comparing the family status the biggest group is the one of the married people (53\%), followed by the $42 \%$ of the single people - widow/widower.

The division of the questioned people in terms of education shows that more than half have secondary school education $(34,8 \%)$ and primary education $(34,8 \%)$. Considerably smaller is the number of the respondents with higher $(11,3 \%)$ and college $(12,8 \%)$ education. Without education are $6,4 \%$. Most of the questioned are pensioners in terms of age $-71,6 \%$, and $14,9 \%$ are pensioners in terms of illness. $13,5 \%$ of the respondents state that they work.

The data from our research show that there prevails the share of respondents living in a city $53,9 \%$, compared to $46,1 \%$ who have stated that their permanent residential place is a village. The research of people from different in distance settlements is connected to the access to medical help - primary and specialized.

In terms of their health condition $60 \%$ of all questioned have registered diseases of the cardiac system, followed by the ones of the endocrinology system $(36 \%)$, respiratory system $(26 \%)$, locomotory system (23\%) and others. Characteristic feature of the pathology in this age diapason is its multiplication. Only $16 \%$ of the respondents have only one disease, $49 \%$ have pointed out two or more, and $35 \%$ more than three.

Within the process of the research the respondents have given assessment of their health. To measure the health self-assessment there has been used a five-gradable scale - very good, good, sufficient, bad and very bad (table 1)

Most of the questioned assess their health condition as good ( $39 \%$ men and $51 \%$ women). It can be noted that with the advancing of the age, the assessments for positive health significantly decline, which is in direct dependence with the increase of the poly-morbid pathology during that age period. Only $4 \%$ of the men and $7 \%$ of the women asked, assess their health as very good.

Table 1. Health self-assessment according to gender (\%)

\begin{tabular}{|c|c|c|}
\hline Health self-assessment & Men & Women \\
\hline Very good & $4 \%$ & $7 \%$ \\
\hline Good & $39 \%$ & $51 \%$ \\
\hline Sufficient & $39 \%$ & $33 \%$ \\
\hline Bad & $18 \%$ & $8 \%$ \\
\hline Very bad & $0 \%$ & $1 \%$ \\
\hline
\end{tabular}

For the elderly people the medical, social and psychological comfort is a guarantee for autonomy and good quality of life. Our research found out that with priority for both genders (men 62\% and women 64\%) are the medical necessities. These prevailing results can again be linked to intensifying the health problems as the age advances.

IRTIIE Vol. 4, No. 4, 2016 ISSN 1314-8788 (print), ISSN 1314-8796 (online), doi: 10.15547/artte.2016.04.011 


\section{ARTTIE $Y$}

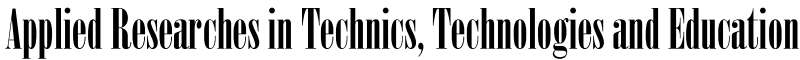

Journal of the Faculty of Technics and Technologies, Trakia University https://sites.google.com/a/trakia-uni.bg/artte/

Every fourth man or woman also needs social necessities, and on third place with hardly $9 \%$ both genders have pointed out the psychological necessities. The results from our questionnaire show surprisingly low levels of social and psychological necessities, which according to a number of authors increase as the age advances. The possible reason is connected to the lack of sufficient and accessible preliminary information about the proposed social services.

The primary prophylactic is the main engagement of the General Practitioner. It is the most important and effective, because the most significant result is achieved when the focus is on it, i. e. not to allow the development of diseases and to promote health. Exactly for this, it is most difficult to be achieved.

The annual prophylactic check-ups are obligatory and are conducted by the GP who is obliged to place in the health institution, somewhere accessible to everyone, information about the type, frequency of the prophylactic check-up and the examined scope. The scope is regulated with Regulation №39 from 2004 with the respective changes and additions.

There appear alarming results, which show that more than $1 / 2$ of the respondents omit their obligatory annual prophylactic check-up. This worrying tendency can also be seen nationally. Reference of the NHIF for two successive years shows that in 2013, 3,523 million Bulgarians have made their prophylactic check-up, and in 2014 - 3,527 million and this tendency remains stable during the following years [5].

More than half of the respondents $(67 \%)$ have shown that they have received information for the prophylactic check-up by the GP when visiting him/her on another occasion, and the other $33 \%$ are not informed.

$44 \%$ of the respondents express their negative assessment from the formal and superficial way of making the prophylactic check-ups and it is probably one of the reasons that they have negligible attitude towards the health prophylactic.

Only $39 \%$ of the respondents think that the prophylactic check-ups are conducted deeply, and the other $17 \%$ don't have clear position about the question.

The sources of health information can be with different level of reliability, from traditional to innovative.

To the question: „What sources do you use to get information for medical prophylactic?" from Fig. 1 it can be seen that most of the respondents get such information from the traditional sources - television (82\%) and radio (25\%). The national TV information campaigns for increasing the social informity, including the risky factors for different diseases, are becoming more and more popular. 39\% of the questioned have pointed out their GP, and the nurse only $14 \%$. It makes impression that $24 \%$ of the respondents have pointed out the Internet. The new technologies are changing the world around us. The opportunities for useful actions are great and the interest for their usage as a source of information acquires greater popularity amongst the group of elderly people.

The total is more than $100 \%$, because the respondents have given more than one answer.

For the elderly people with chronic diseases the training for self-observation and self-control is important for the effective managing of the risk from complications and is a good prerequisite for good quality of life in the backgrounds of the chronic pathology. It is important to note the data of $52 \%$ of the questioned people who have stated that they have never been trained about health-cares for the disease, bigger is the share of the ones living in a village. All respondents who have given positive answer and confirmed a conducted training by a medical specialist have also answered the next question: „How did you get the health information? - The results show that a health discussion is the most widely applied way of supplying health information from the medical specialists with $40 \%$ of the respondents. Then come the brochures - $33 \%$, hardly $3 \%$ have pointed out health-educational film, and the other $25 \%$ have chosen something else without specifying the form. 


\section{IRTIIE}

Ipplied Researleches in Technics, Technologies and Rduciation Journal of the Faculty of Technics and Technologies, Trakia University https://sites.google.com/a/trakia-uni.bg/artte/

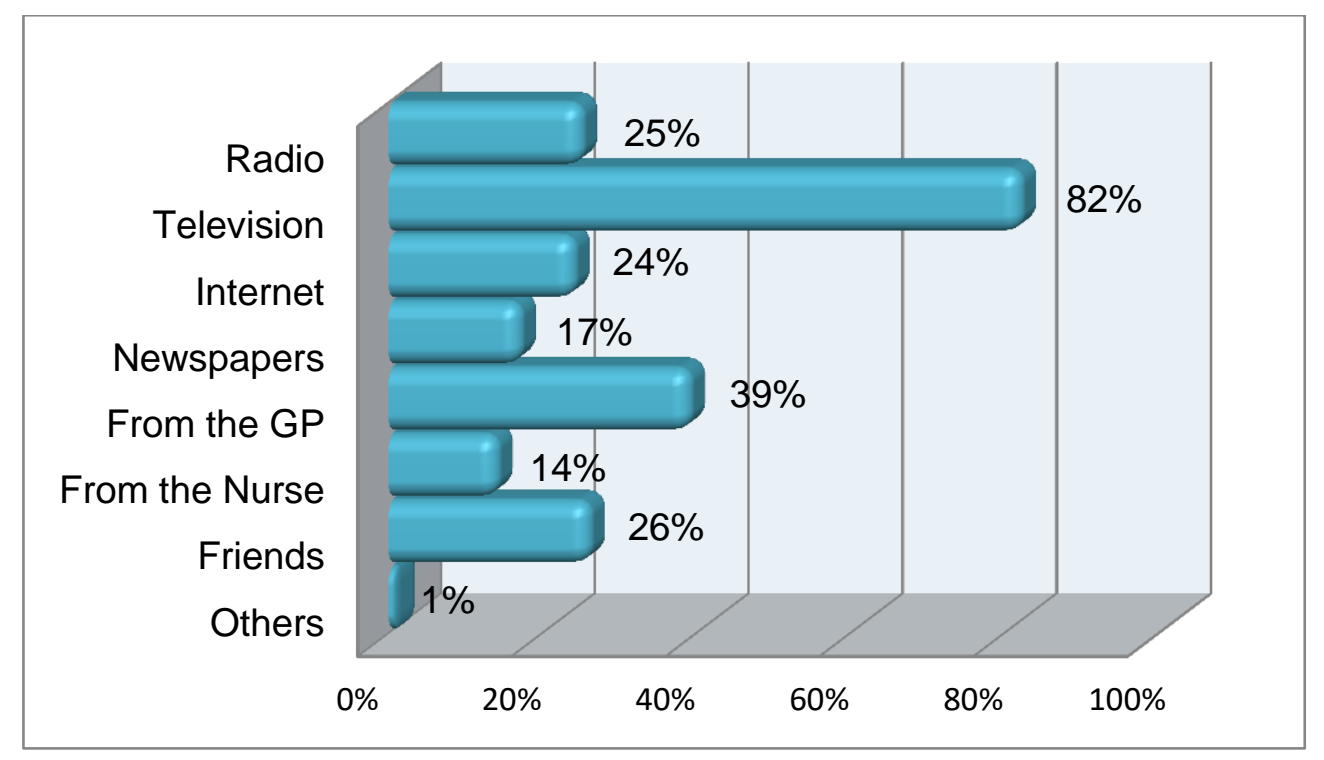

Figure 1. „What sources do you use to get information?“

To the question: „What sources of information do you prefer?"- Fig.2 The highest is the relative share of people who choose to trust their GP (51\%), after that comes the nurse (30\%).

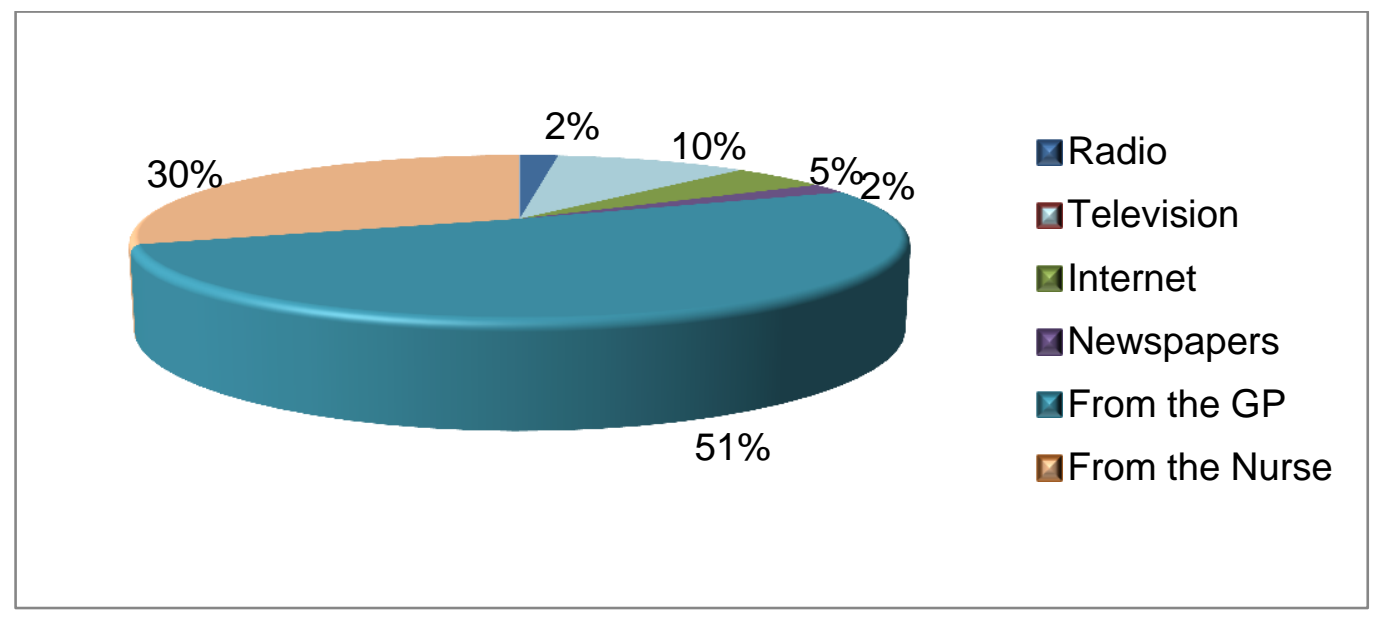

Figure 2. Preferable source of informing

The trust to the medical specialists is the rightest choice when it comes to giving medical information. This gives an opportunity for individual approach and positive impact over the personal motivation, especially in the cases of a necessity from transforming behavior on behalf of the health.

Important task for the contemporary medicine and healthcare is the fight against the preliminary ageism. The prophylactic of the preliminary ageism must start in the early stages of the ontogenesis and can be redirected to the medical control of the risk factors and timely correcting activities with devitalized way of life.

Considerable differences in the informity for the risk factors for premature ageing can be noted in terms of educational system, $67 \%$ from the respondents with a lower educational level, don't even know the risk factors (Fig. 3)

IRTIIE Vol. 4, No. 4, 2016 ISSN 1314-8788 (print), ISSN 1314-8796 (online), doi: 10.15547/artte.2016.04.011 


\section{IRTIIE}

Ipplied Reseirl'ches in Technics, Technologies and Bduration Journal of the Faculty of Technics and Technologies, Trakia University https://sites.google.com/a/trakia-uni.bg/artte/

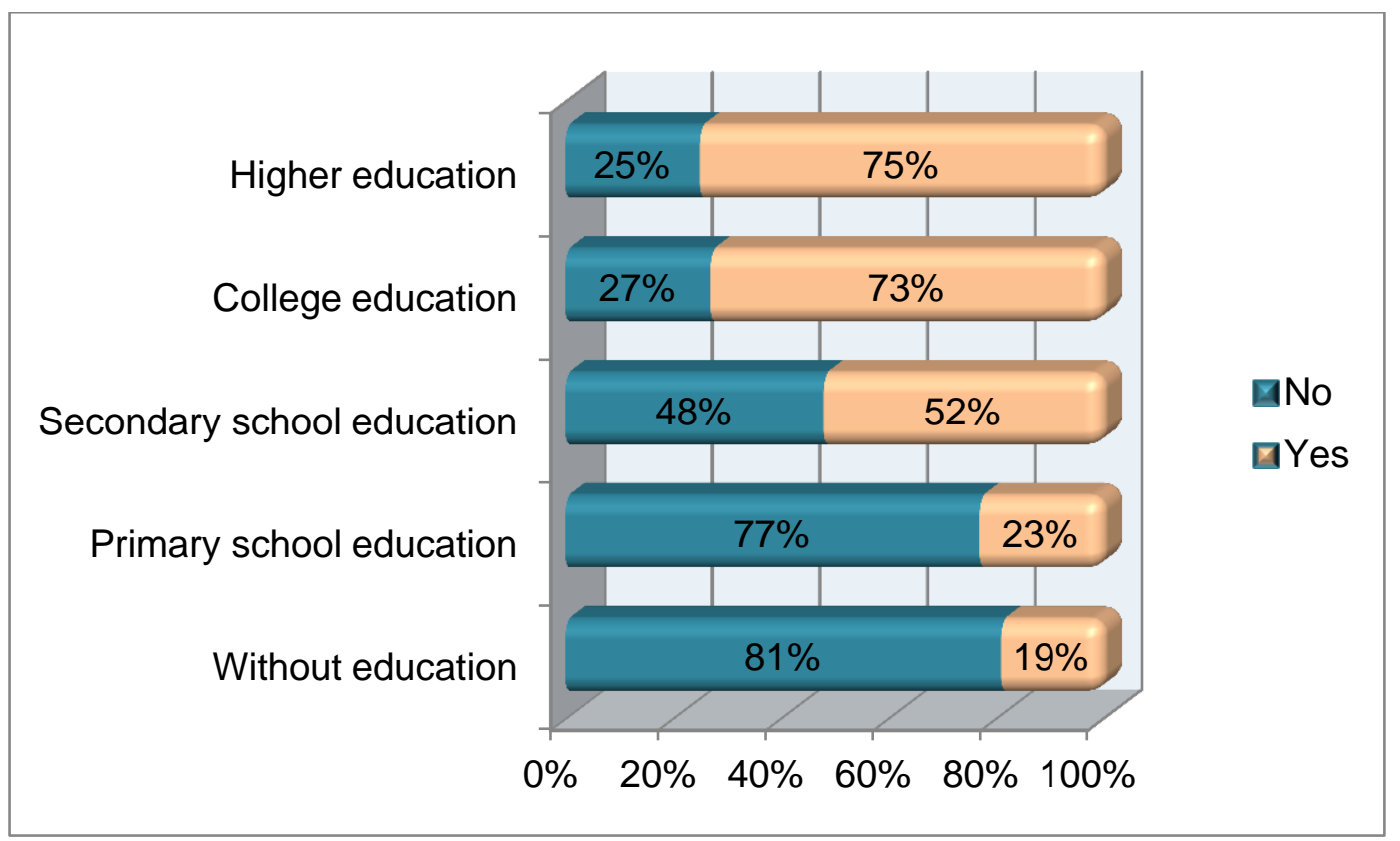

Figure 3. Educational degree and informity about the risk factors for premature ageing

Considerable parts of Bulgarians live in places where there are no General Practitioners. These are usually remote and deserted areas with small populations. In such cases the opportunities that they have are: choosing a GP from another region or a GP who regularly on a schedule visits the settlement, but in both cases the discomforts, obstacles and the increased health risk are on behalf of all people living in these "unattractive regions".

From the viewpoint of residence there has also been defined considerable difference in the informity about the risk factors (Fig.4). The respondents from the cities are informed to a greater extent. This proves the necessity from conducting a health-educational activity in the rural regions where mostly live old people, with low level of education and deteriorated social and economic status. Combining the stated problems above reflects to a different extent the level of health culture and at the same time impedes the prophylactic activities. The efforts of the medical specialists in this direction must be aimed at increasing the health knowledge and motivation for health behavior.

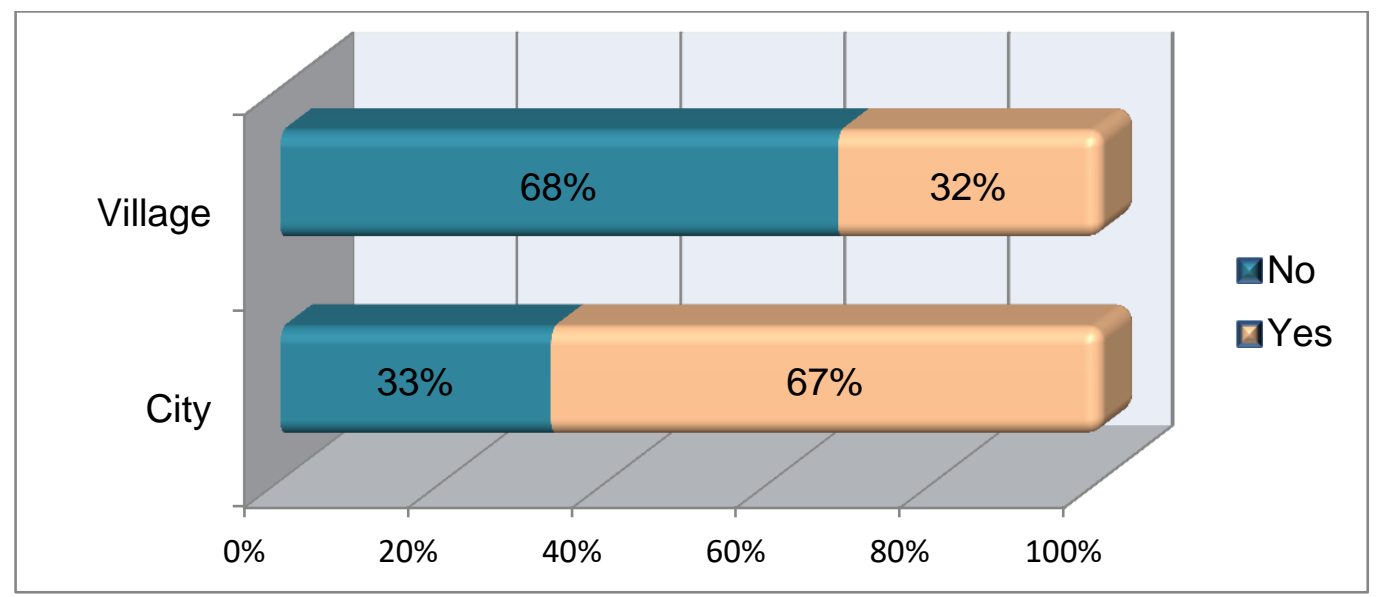

Figure 4 Residence and informity about the risk factors for premature ageing IRTIIE Vol. 4, No. 4, 2016 ISSN 1314-8788 (print), ISSN 1314-8796 (online), doi: 10.15547/artte.2016.04.011 


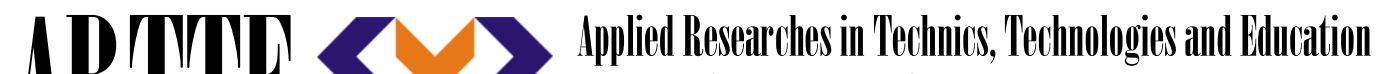 Journal of the Faculty of Technics and Technologies, Trakia University https://sites.google.com/a/trakia-uni.bg/artte/}

The main aims of the health education are to motivate people to lead nature-friendly way of life, to change their risk form of behavior and realize the necessity from taking personal responsibility for their health. That's why the health information that the society needs must be easily accessible, be compatible with the intellectual level of the group at which it is targeted and be complete enough [4].

The results from the research give us ground to state that:

- Health prophylactic is not so well-used medical activity that is fundamental and of greatest significance for achieving good health, prevention from diseases and premature ageing.

- The relative share of people who have knowledge for the risk factors for premature ageing is relatively small.

- The main source for information is the media, but the respondents clearly declare preferences, readiness and desire to be informed by the medical specialists - a doctor and a nurse. Their contribution in the health-educational direction at the present moment is at a very insufficient level, too modest and with hidden potential.

\section{CONCLUSION}

For the contemporary modern and preventive healthcare, informing and knowledge are fundamental for all age phases and are a guarantee for reducing the "patients' mistakes", preventing obstacles and deteriorated quality of life.

\section{REFERENCES}

[1] Musov V., Contemporary projections and social - economic results from the implementation of the new information technologies in healthcare, auto-paper Blagoevgrad 2012.

[2] Paskaleva T., Analysis and assessment of the prophylactic activity of the elderly people Jubilee scienticfic conference for lecturers, students and specialuists in the healhcare with international participation - 10 years specialty „Medical laboratory assistant “ in Medical college - Stara Zagora, October 2016.

[3] Regulation of the MH № 39 from 16th November 2004 г. for the prophylactic check-ups and dispensary.

[4] Vizeva M., Quality of life and management of the healthcares for diabetes Type two, auto-paper, Sofia 2014.

[5] http://www.nursing-bg.com/na754.html. 